1. Research Officer PMRC Research Centre, FJMC, Lahore.

2. Senior Registrar (Eye), Sir Ganga Ram Hospital, Lahore.

3. Research Officer PMRC Research Centre, FJMC, Lahore.

4. Research Director, PMRC Research Centre, FJMC, Lahore.

5. Statistician,

PMRC Research Centre,

FJMC, Lahore.

Correspondence Address:

Muhammad Adnan,

Research Officer,

PMRC Research Centre,

FJMC, Lahore.

adiprince81@gmail.com

\section{DIABETIC EYE SCREENING IN SIR GANGA RAM HOSPITAL, LAHORE.}

Mr. Muhammad Adnan', Dr. Humera Zafar' ${ }^{2}$, Mrs. Zahra Ali ${ }^{3}$, Dr. Iffat Shabbir ${ }^{4}$, Ms. Tayyaba Rahat ${ }^{5}$

ABSTRACT... Background: Diabetic retinopathy is the optical complication that may lead to impaired vision. It is one of the most prevalent but preventable blinding disease. Its early diagnosis is prerequisite for the prevention of the visual loss and blindness associated with diabetic complication. Objective: To estimate frequency of eye examination and various types of retinopathy; and to find the association between diabetic retinopathy and its risk factors. Methods: The cross sectional study was conducted from Apr-Sep 2012 by PMRC Research Centre, FJMC, Lahore. Using non probability convenient sampling, eighty known type II diabetics were recruited. Venous blood was drawn for plasma glucose level (GOD-PAP) and glycosylated hemoglobin (lon-Exchange Resin). Arterial blood pressure was measured using digital apparatus (Oscillometric method). Visual acuity was tested by Snellen's chart and dilated fundus examination was done to screen diabetic retinopathy. Data was analyzed using Statistical Package for Social Sciences (SPSS-20). Results: The study included $41 \%$ males and $59 \%$ females. Mean age was 51 \pm 9 (33-67) years. Diabetics who never screened for retinopathy were $54.3 \%$; and who examined during last year as per IDF guidelines were $25.7 \%$. The frequency of bilateral and unilateral NPDR was $22.5 \%$ and $5 \%$, respectively. The occurrence of NPDR was slightly higher in left eye, whereas PDR was more prevalent in right eye. The visual acuity was equal or better than 6/12 in better eye of $80 \%$ study participants; and was 6/18-6/36 in better eye of $20 \%$ participants. DR was significantly associated with longer duration of diabetes ( $p-0.010)$, poorly controlled diabetes ( $p-0.044)$ and hypertension ( $p-0.006)$. Odd ratios $(95 \% \mathrm{Cl})$ showed that duration of diabetes $\geq 20$ years, glycosylated hemoglobin $\geq 7.5 \%$, Systolic blood pressure $\geq 140 \mathrm{~mm} /$ $\mathrm{Hg}$ and diastolic blood pressure $\geq 90 \mathrm{~mm} / \mathrm{Hg}$ had $3-5$ times higher risk of retinopathy. Conclusion: Majority of patients were neither knew nor referred for eye examination. Strict control of diabetes and hypertension may prevent or delay diabetic retinopathy. Policy Message: Annual eye examination must be prescribed by the physician/ diabetologist. An education and awareness program for diabetics and community based survey is highly recommended.

Key words: Diabetic Retinopathy, Non-proliferative Diabetic Retinopathy, Proliferative Diabetic Retinopathy, Duration of Diabetes, Eye Examination.

Article Citation: Adnan M, Zafar H, Ali Z, Shabbir I, Rahat T. Diabetic Eye Screening in Sir Ganga Ram Hospital, Lahore. Professional Med J 2014;21(5):941-945.

\section{INTRODUCTION}

Diabetic retinopathy (DR) is damage to fragile blood vessels of retina due to long term diabetes. It is a leading cause of adult blindness in United States ${ }^{1}$, Australia ${ }^{2}$, Israel ${ }^{3}$ and Western World. ${ }^{4}$ Pakistan ranks $6^{\text {th }}$ among countries with diabetes ${ }^{5}$.More than $10 \%$ of its adult population have diabetes ${ }^{6}$. Patients with both type 1 diabetes mellitus (T1DM) and type 2 diabetes mellitus (T2DM) are at high risk for this condition. All studies have shown similar risk factors for DR such as duration of diabetes, glycemic status and hypertension $(\mathrm{HTN})^{7-10}$. In T2DM $21 \%$ patients have DR at diagnosis ${ }^{11}$ and $>60 \%$ patients in first 20 years of disease ${ }^{12}$.The duration of diabetes is the factor that cannot be customized while glycemic control and HTN can be tailored. Reduction in progression and severity of retinopathy is seen when glycemic control maintained less than $7 \%^{13}$ and blood pressure controlled tightly independent of the use of angiotensin converting enzyme (ACE) inhibitors ${ }^{14}$.

Several types of screening programs have been designed throughout the world to meet this problem. In Pakistan, population-based data on the prevalence of DR is limited. A comprehensive program of screening followed by prompt and 
adequate treatment can make a significant contribution to eradicate DR as a cause of blindness.

\section{Objectives}

The study was designed to estimate the frequency of eye examination and various types of retinopathy; and to find the association between diabetic retinopathy and its risk factors.

\section{MATERIALS AND METHODS}

The cross sectional study was conducted from April 2012 to September 2012 at PMRC Research Centre, FJMC, Lahore in collaboration with Eye Department of Sir Ganga Ram Hospital, Lahore. Using non probability convenient sampling, eighty known type II diabetics who consented to be participant of the study, were recruited. A specially designed proforma was used as study tool to collect data for age, gender, education, socioeconomic status, duration of diabetes, prescription pattern, family history of disease and frequency of eye examination. Venous blood sample $(5 \mathrm{ml})$ was drawn to estimate plasma glucose (GOD-PAP method) and glycosylated hemoglobin (Ion-Exchange Resin method). Arterial blood pressure was measured using digital apparatus (Oscillometric method). Visual acuity was tested by Snellen's chart and dilated fundus examination was done to screen diabetic retinopathy.

Data analysis was done using the Statistical Package for Social Sciences (SPSS 20). Age was described by using Mean $\pm S D$; Eye examination and retinopathy were illustrated by frequency (percentage). Fisher exact test was used for association between retinopathy and risk factors. Odd ratio was calculated with $95 \%$ confidence interval. $\mathrm{P}$-Value $\leq 0.05$ was considered significant.

\section{RESULTS}

The study included 80 type II diabetics, among them 33 (41\%) were males and 47 (59\%) were females. The mean age was $51 \pm 9(33-67)$ years. Among respondents $30 \%$ were illiterate and $55 \%$ were of low socioeconomic status. Frequency of family history of diabetes, hypertension, cardiovascular and renal disease was $78 \%, 63 \%$, $48 \%$ and $15 \%$ respectively. Among recruited diabetics $88 \%$ were hypertensive; only $53 \%$ were known hypertensive; and $35 \%$ were diagnosed as hypertensive at the time of registration. For treatment it was observed that $55 \%$ patients were taking only oral hypoglycemic drugs (metformin and/or sulfonylurea), $20 \%$ were taking only insulin (70/30 humulin) and $20 \%$ were taking combination therapy (metformin and insulin). However 5\% were not taking any medicine at all.

Seventy diabetics with duration of diabetes more than two years answered the question, "have you ever examined for retinopathy and if yes when last time?" It was seen that $54.3 \%$ diabetics were never examined; $5.7 \%$ were examined since more than two years; $14.3 \%$ were examined within one to two years; and $25.7 \%$ were examined during twelve months prior to recruitment for study. (Table I).

\begin{tabular}{|c|c|c|c|}
\hline \multirow{5}{*}{$\begin{array}{l}\text { Eye Examination } \\
\qquad(n=70)\end{array}$} & No & 38 & $.3 \%)$ \\
\hline & \multirow{4}{*}{ Yes } & \multicolumn{2}{|c|}{32 (45.7\%) } \\
\hline & & $>02$ years & 04 (5.7\%) \\
\hline & & $1-2$ years & 10 (14.3\%) \\
\hline & & $<01$ year & 18 (25.7\%) \\
\hline
\end{tabular}

Table-I. Frequency of diabetic eye screening

In total 160 eyes of 80 study participants were examined by dilating pupils. No abnormality was seen in $76(47.5 \%)$ eyes. The overall incidence of DR, NPDR, PDR and CSME was $32.5 \%, 25 \%$, $6.3 \%$ and $1.2 \%$, respectively. The frequency of bilateral and unilateral NPDR was 22.5 and 5\%, respectively. The NPDR was seen $5 \%$ more in left eye where as PDR was $2.5 \%$ more prevalent in right eye. The incidence of cataract alone was observed in $20 \%$; however cataract was also seen in both eyes along with retinopathy. (Table II).

The visual acuity was equal or better than $6 / 12$ in better eye of $80 \%$ study participants; and was $6 / 18-6 / 36$ in better eye of $20 \%$ participants. (Table III). 


\begin{tabular}{|c|c|c|c|c|}
\hline & & Left Eye $(n=80)$ & Right Eye $(n=80)$ & Total $(n=160)$ \\
\hline NAD & & 38 (47.5\%) & 38 (47.5\%) & 76 (47.5\%) \\
\hline \multirow{3}{*}{ NPDR } & Only & $04(5.0 \%)$ & $04(5.0 \%)$ & $08(5.0 \%)$ \\
\hline & Cataract & $14(17.5 \%)$ & $12(15.0 \%)$ & $26(16.2)$ \\
\hline & CSME & $04(5.0 \%)$ & $02(2.5 \%)$ & $06(3.8 \%)$ \\
\hline \multirow{2}{*}{ PDR } & Cataract & $02(2.5 \%)$ & $04(5.0 \%)$ & 06 (3.8\%) \\
\hline & CSME & $02(2.5 \%)$ & 02 (2.5\%) & 04 (2.5\%) \\
\hline CSME & Only & 0 & $02(2.5 \%)$ & $02(1.2 \%)$ \\
\hline Cataract & Only & $16(20.0 \%)$ & $16(20.0 \%)$ & 32 (20.0\%) \\
\hline \multicolumn{5}{|c|}{$\begin{array}{l}\text { Table-II. Prevalence of diabetic retinopathy and other eye complications } \\
\text { NAD=No Abnormality Detected; NPDR=Non-proliferative Diabetic Retinopathy; } \\
\text { R=Proliferative Diabetic Retinopathy; CSME=Clinically Significant Macular Edema. }\end{array}$} \\
\hline
\end{tabular}

\begin{tabular}{|c|c|c|}
\hline Visual Acuity & $\begin{array}{c}\text { Left Eye } \\
(\mathbf{n = 8 0})\end{array}$ & $\begin{array}{c}\text { Right Eye } \\
(\mathbf{n = 8 0 )}\end{array}$ \\
\hline $6 / 6$ & $20(25.0 \%)$ & $26(32.5 \%)$ \\
\hline $6 / 9$ & $16(20.0 \%)$ & $20(25.0 \%)$ \\
\hline $6 / 12$ & $20(25.0 \%)$ & $18(22.5 \%)$ \\
\hline $6 / 18$ & $10(12.5 \%)$ & $06(7.5 \%)$ \\
\hline $6 / 24$ & $04(5.0 \%)$ & $04(5.0 \%)$ \\
\hline $6 / 36$ & $10(12.5 \%)$ & $06(7.5 \%)$ \\
\hline & \multicolumn{2}{|c|}{ Table-III. Visual Acuity } \\
\hline
\end{tabular}

The results have shown that diabetic retinopathy was significantly associated with duration of diabetes, glycosylated hemoglobin, systolic blood pressure and diastolic blood pressure. However odds ratio of duration of diabetes $\geq 20$ years (OR 4.3, 95\% Cl); HbA1c (OR 2.7, 95\%Cl); Systolic blood pressure (SBP) (OR 5.1, 95\% $\mathrm{Cl}$ ) and diastolic blood pressure (DBP) (OR 4.2, 95\% Cl) revealed that patients having history of diabetes for 20 years or more had 4-times greater chances of having retinopathy; and poor glycemic control (HbA1c $7.5 \%$ or above) had 3-times more chance of retinopathy. Similarly, SBP and DBP elevated beyond their optimal levels had 4-5 folds higher risk of retinopathy. (Table IV).

\begin{tabular}{|c|c|c|c|}
\hline Risk Factors & Variables & Odd Ratio & P-value \\
\hline Duration of disease & Duration of diabetes $\geq 20$ years & $4.3(95 \% \mathrm{Cl}, 1.34-13.44)$ & $0.010^{*}$ \\
\hline \multirow{2}{*}{ Glycemic Control } & Plasma glucose random $\geq 200 \mathrm{mg} / \mathrm{dl}$ & 0.7 (95\% Cl, 0.30-1.81) & 0.468 \\
\hline & Glycosylated hemoglobin $_{\geq 7.5 \%}$ & $2.7(95 \% \mathrm{Cl}, 1.00-7.22)$ & $0.044^{*}$ \\
\hline \multirow{2}{*}{ Hypertension } & Systolic blood pressure $_{\geq 140 \mathrm{~mm} / \mathrm{Hg}}$ & $5.1(95 \% \mathrm{Cl}, 1.56-16.91)$ & $0.006^{*}$ \\
\hline & Diastolic blood pressure $_{\geq 90 \mathrm{~mm} / \mathrm{Hg}}$ & $4.2(95 \% \mathrm{Cl}, 1.49-12.28)$ & $0.009^{*}$ \\
\hline
\end{tabular}

\section{DISCUSSION}

Only $25.7 \%$ diabetics had been screened for retinopathy during last year while International Diabetes Federation guideline recommends that screening for retinopathy should start after two years diabetes duration and frequency of retinopathy screening in general should occur annually ${ }^{15}$. Majority of diabetics (54.3\%) as in Malaysia $(55.0 \%)^{16}$ had never been examined for retinopathy because they were neither knew nor referred to eye clinic. The diabetics $(20 \%)$, who were screened before one year or more, underwent fundus screening after the incidence of eye complication.

DR prevalence (32.5\%) found in study was slight higher but comparable to $28.6 \%$ in Chandka Medical College, Larkana ${ }^{7} ; 28.9 \%$ in Jinnah Hospital, Lahore 10; and $29.8 \%$ in Medical University, China ${ }^{17}$. The incidence of DR, PDR and macular edema $41 \%, 7 \%$ and $10 \%$ was higher in Irish Type II diabetics; however visual acuity equal or better than $6 / 12$ in better eye was lower $(91 \%$ $<80 \%)$ in studied diabetics ${ }^{4}$. Results showed that long duration of diabetes, poor glycemic control and uncontrolled blood pressure were 
significantly associated with diabetic retinopathy. These risk factors had also been proved in different studies ${ }^{17-19}$. Duration of diabetes cannot be modified but other two factors can be ordered. Therefore, good control of plasma glucose and blood pressure can improve the outcome.

Severe vision loss and moderate vision loss from diabetes are essentially preventable with timely detection and treatments, careful longterm follow-up and comprehensive diabetes mellitus care firmly based on clinical evidence. Future treatments, as outgrowths of further understanding of the biochemical basis of the disease, will aim at curing or preventing retinal complications from diabetes ${ }^{20}$.

\section{CONCLUSION}

The frequency of retinopathy screening was extremely low. Majority of patients were neither knew nor referred for eye examination. Strict control of diabetes and hypertension may prevent or delay diabetic retinopathy. Annual eye examination must be prescribed by the physician/ diabetologist. An education and awareness program for diabetics and community based survey is highly recommended.

Copyright(C) 25 Aug, 2014.

\section{REFERENCES}

1. Klein R, Moss SE, Klein BE. New management concepts for timely diagnosis of diabetic retinopathy treatable by photocoagulation. Diabetes Care. 1987 Sep-Oct; 10(5):633-8.

2. Harper CA, O'Day J, Taylor HR. Early detection of diabetic retinopathy. Med J Aust. 1995 May 15; 162(10):536-8.

3. Jaime Levy, Tova Lifshitz, Dan Goldfarb, Boris Knyazer, Nadav Belfair. Screening For Diabetic Retinopathy with a Mobile Non-Mydriatic Digital Fundus Camera in Southern Israel. IMAJ 2011; 13: 137-140.

4. Kristinsson JK. Diabetic retinopathy. Screening and prevention of blindness. A doctoral thesis. Acta Ophthalmol Scand Suppl. 1997;(223):1-76.

5. Wild S, Roglic G, Green A, Sicree R, King H. Global prevalence of diabetes: estimates for the year 2000 and projections for 2030. Diabetes Care 2004; 27(5):1047-53.

6. Shera AS, Rafique G, Khwaja IA, Baqai S, Khan IA, King
H. Pakistan National Diabetes Survey prevalence of glucose intolerance and associated factors in North West at Frontier Province (NWFP) of Pakistan. J Pak Med Assoc 1999; 49(9):206-11.

7. Aftab Hussain Shah, Partab Rai, Azizullah Jalbani, Imdad Ali Ansari, Kouromal Gurbakhshani, Bashir Ahmed Shaikh. Risk factors of diabetic retinopathy in diabetes mellitus. Medical Channel. 2010 JulySeptember; 16 (3):362-64.

8. Jamal-u-Din, Mohammad Babar Qureshi, Akhtar Jamal Khan, Mohammad Daud Khan, Khabir Ahmad. Prevalence of diabetic retinopathy among individuals screened positive for diabetes in five communitybased eye camps in northern Karachi, Pakistan. $J$ Ayub Med Coll Abbottabad 2006; 18(3).

9. Abdul Qayyum, Amir Muhammad Babar, Gurmak Das, Abdullah Jan Badini. Prevalence of Diabetic Retinopathy in Quetta Balochistan. Pak J Ophthalmol 2010; 26(4).

10. Ghulam Mohyuddin Chaudhary. Retinopathy in Diabetic patients. Pakistan J. Med. Res. 2005; 44(2).

11. Standards of Medical Care for Patients With Diabetes Mellitus. Diabetes Care 2002; 25(90001):33S-49.

12. Fong DS, Aiello LP, Ferris FL, 3rd, Klein R. Diabetic retinopathy. Diabetes Care 2004; 27(10):2540-53.

13. Stern Mp, Gonzalez C, Mitchell BD, Vilal Pando E, Hattnerr SM, Hazuda HP: Genetic and Environmental determinants of Type-II Diabetes in Mexico City and sanantonio, Diabetes 1992; 41: 484 - 492.

14. Mathew DR, Stratton IM, Aldington Sj, Holman RR, Kohner EM. Risks of progression of retinopathy and vision loss related to tight blood pressure control in type-II DM. UKPDS 69. Arch Ophthalmol 2003; 122: $1631-40$.

15. http://www.idf.org/webdata/docs/IDF\%20GGT2D.pdf

16. Goh P P, Omar M A, Yusoff A F. Diabetic eye screening in Malaysia: findings from the National Health and Morbidity Survey 2006. Singapore Med J 2010; 51(8): 631-634.

17. Liu L, Liu LM, Hu YD, Hua R, Chen J, Zhou Y, et al. Hospital based epidemiological study for diabetic retinopathy: study design and preliminary results. Int J Ophthalmol. 2011;4(5):543-5.

18. Muawyah D. Al-Bdour. Maha I. Al-Till. Khawla M. Abu Samra. Risk factors for Diabetic Retinopathy among Jordanain Diabetics. Middle East Afr J Ophthalmol. 2008 Apr-Jun; 15(2): 77-80. 
19. Al-Adsani AM. Risk factors for diabetic retinopathy in Kuwaiti type 2 diabetic patients. Saudi Med J. 2007 Apr;28(4):579-83.
20. Aiello LM. Perspectives on diabetic retinopathy. Am J Ophthalmol. 2003 Jul;136(1):122-35.

\section{CORRECTION}

The amendment of the Professional Vol: 21, No.03 (Prof-2473) on page 580 is as under;

\section{INCORRECT}

Dr. Saima Perveen ${ }^{2}$ MBBS, MCPS, FCPS

Associate Professor of Obs/Gynae

Mohterma Benazir Butto Hospital, Mirpur

\section{CORRECT}

Dr. Saima Perveen ${ }^{2}$ MBBS, MCPS, FCPS

Assistant Professor of Obs/Gynae

Mohterma Benazir Butto Shaheed Medical College, Mirpur, AJK

\section{You never fail until you stop trying.}

